\title{
Factors Affecting the Strength of Production - Oriented Savings Groups in the Upper North Thailand
}

\author{
Thanes Sriwichailamphan $^{1 *}$ and Thunyawadee Sucharidtham ${ }^{2}$ \\ ${ }^{1}$ School of Economics, Chiang Mai University, Thailand \\ ${ }^{2}$ Faculty of Business Administration and Liberal Arts, Rajamangala University of Technology Lanna, Thailand
}

\begin{abstract}
The Saving for Production Group is one of the micro finance organizations of Thailand which operates financial activities in providing services to its members gathering from the villagers in order to assist one another. In order to create the foundation of the country development, the group encourages all members to economize and save the money together every month, reinforces the ability, and utilizes the resources in developing their own quality of life. This research mainly aimed to examine the factors influencing the strength, management description, operation, debt and property management, working barriers, and need in assistance of the saving for production groups in upper northern areas of Thailand. The research was conducted by using the questionnaires to interview the presidents, secretaries or the group committee level 3 from 650 saving for production groups. Logit model was applied in the study to analyze the factors affecting the strength of the groups. The findings revealed that the factors influencing the saving for production groups to have an increase in the strength. The most influential factor was appropriate management and thorough distribution of welfare for its member to strengthen the group $\left(X_{21}\right)$. This allowed the groups to possess an increase in strength of the groups at $30.43 \%$. However, there were several factors affecting the groups to have a decrease in strength including the acquisition of the saving for production group's committee $\left(\mathrm{X}_{5}\right)$, rule and regulation setting $(\mathrm{X} 8)$, members' participation in decision making on operation $\left(\mathrm{X}_{10}\right)$, and participation in trainings, seminars, and observation activities related to capital management of the committee in the past year $\left(X_{17}\right)$. These resulted in a decrease in the groups' strength at $5-1 \%$.
\end{abstract}

Keywords: Savings group; Production; Property management

\section{Introduction}

In Thailand, by Department of Community Development, Ministry of Interior, there is the promotion of establishing the saving for production groups which are micro finance organizations in the villages around the country $[1,2]$. The groups, founded from the gathering of the villagers, aim to conduct financial activities in order to help one another, encourage the members to economize and save the money every month. Besides, the saving becomes the capital for the members who are in need or with trouble to take on a loan for investing, carrying on their occupation, or improving their prosperity and their family's welfare.

The groups became more important when there was an economic crisis in Thailand in 1997 resulting in the problem of unemployment. Most of the unemployed were from rural areas and they had to return their hometown. They were also poor and lacked the opportunities to access the sources of investment funds to develop themselves and their occupation. The reason was that the commercial banks and financial institutions were unable to provide the services covering the rural areas thoroughly. At the same time, those financial institutions were likely not to distribute the credits to the needy because they had the careers with unstable income and lacked the mortgage securities. Depending on local loan shark, those people were taken advantages. These problems had led the community to discover the importance of self dependence and gathered to establish their financial groups in their won villages where the money was used as a major mechanism means for the needy to get together as a group, to reinforce the ability of one another, and to utilize the resources in developing their own quality of life. This addressed the development from the foundation which would result in the country development in the future.

The saving for production group was first established in a village of Chiang Mai in 1974. Later, the number of establishment was expanded and there have currently been 29,534 groups including 4,512,883 members with 38,762 million Baht of the saving by all group members
(Department of Community Development) [3,4]. This regards as a small financial organization which has spread and most covered the rural areas when compared with other small financial organizations. The concept of the saving for production groups is based on that of agricultural cooperatives and combined with that used for establishing credit union groups. The concept of the saving for production groups can be divided into 4 parts. The first concept is that the group allows people in community to gather in order to help one another and emphasizes the understanding of "social capital" among those people. The second concept deals with providing financial support to the underprivileged or the poor by the means of creating the groups with saving and allocating the saving as loan for the members who are in need based on the principle of sympathy. The third concept is that it is the practice leading to intelligent working process which helps the members to find out the channels of investment by themselves. The last concept is the practice which allows the households to know how to live in a quality way of life from participating in several activities together which regards as the source of the products from the villagers and as the practice to obtain more knowledge in trading. According to the development of the saving for production groups, the Department of Community Development has divided the group into 3 levels. Level 1 contains the initial groups without development; level 2 includes the groups with somewhat development and additional development required; and level 3 comprises the well-developed groups. Although

*Corresponding author: Thanes Sriwichailamphan, School of Economics, Chiang Mai University, 50200, Thailand, Tel: 053-942208; E-mail: thunyawadee@gmail.com

Received November 02, 2015; Accepted December 29, 2015; Published January 04, 2016

Citation: Sriwichailamphan T, Sucharidtham T (2016) Factors Affecting the Strength of Production - Oriented Savings Groups in the Upper North Thailand. Int J Econ Manag Sci 5: 313. doi:10.4172/2162-6359.1000313

Copyright: (C) 2016 Sriwichailamphan T, et al. This is an open-access article distributed under the terms of the Creative Commons Attribution License, which permits unrestricted use, distribution, and reproduction in any medium, provided the original author and source are credited. 
a lot of saving for production groups has been completely developed to level 3, it does not mean that they possess the financial strength. Consequently, this research was interested in examining the factors that affect the strength in operating the saving for production groups. The level-3 groups in the northern areas were samples used in the study. Moreover, the study would address management description, problems, and working barriers and the findings would be later applied in making policies related to fundamental financial system development as well as finding proper and beneficial patterns that meet the real needs of the fundamental community [5-8]. This would eventually allow the ability to develop the groups sustainably and stably.

\section{Concepts of the Saving for Production Groups}

The Saving for Production Group is one of the micro finance organizations of Thailand which operates financial activities in providing services to ones with low income or minor entrepreneurs. The group is generally founded from the gathering of villagers in order to assist themselves and help one another by learning to economize and save the money together gradually and regularly. The main purpose of the group is to create the capital for its members who are in need to take on loan and invest in their own occupation, or spend it as their prosperity and family's welfare. The groups started playing an important role when there was an economic crisis in Thailand in 1997 resulting in the problem of unemployment. Most of the unemployed were from the rural areas and they had to return their hometown. They were also poor and lacked the opportunities to access the sources of investment funds to develop themselves and their occupation. The reason was that it was not cost-effective for the commercial banks and financial institutions to launch new branches and provide the services covering the rural areas thoroughly. Those financial institutions were also likely not to distribute the credits to the poor because they had the careers with unstable income lacked the mortgage securities. Depending on local loan shark, they were extremely taken advantages. These causes led the community to discover the importance of self dependence and gather to establish their saving groups, saving for production groups, community banks, and credit union groups [9-12]. These groups are used as a major mechanism means for the needy to get together as a group, to reinforce the ability of one another, and to utilize the resources in developing their own quality way of life. This addressed the development from the foundation which would result in the country development in the future.

The concepts of the saving for production group can be divided into 4 parts as follows.

The first concept is to provide people in the community an opportunity to gather and assist one another as a result of a big difference in economic status of each community that some households are rich while others are poor. This concept of the group focuses on promoting the understanding of "social capital".

The second concept deals with the financial support provided to the underprivileged or the needy. In fact, people in the community are basically assisted by the agricultural financial institutions, yet the assistance is not distributed thoroughly, especially to those who are poor and have no ownership of the lands. This leads them to depend on the loan with extremely high interest from the capitalists. Therefore, the gathering of people in the group allows them to have their own saving and allocate the saving to the members in need of loan based on the principle of sympathy.

The third concept relates to the practice of working procedure in a wise way. After the members have got the loans from the group, they are necessary to practice careful thinking process of how to invest the capital in their occupation in order to obtain higher yield upon the investment than the interest that they have to pay. This practice will help the members learn more how to find channels of investment by themselves.

The last concept is to train the households to learn how to live a quality life. The gathering of the members brings them to cooperate in several activities, especially the exchange of goods. The foundation of the marketing demonstration center is one of the group's activities. The center is the source of goods from the villagers and the place where they can learn more how to trade [13-15].

\section{Data Analysis}

To analyze the factors affecting the strength in the saving for production groups in upper northern areas, the study applied the Logit model to examine those factors because the variables in this research [16-18] possessed the possibility value between 0 and 1 . The method was also popular to be used in the analysis regarding the factors influencing any acceptance or refusal, the factors resulting in any achievement, or the factors affecting purchase decision making. Moreover, the analysis using Ordinary Least Squares method (OLS) is an incorrect predicting way because the predicted values of the dependent variables in this equation have the possibility to be less than 0 and higher than 1 , so Logit model was eventually applied in this study when the equation is as follows.

$$
\mathrm{y}_{\mathrm{i}}=\mathrm{x}_{\mathrm{i}} \beta+\mu_{\mathrm{i}}
$$

Practically, $y_{i}$ value is directly unobservable, but we can observe it from the fact that the saving for production group has the strength which is measured by the indicators. Then, the dummy variable was applied in the analysis when $\mathrm{y}_{\mathrm{i}}$ was a dependent variable.

If $y_{i}=1$, that means the saving for production groups possess strength.

If $y_{i}=0$, that means the saving for production groups possess no strength.

From Likelihood function,

$$
\begin{aligned}
& \operatorname{Prob}\left(\mathrm{y}_{1},=\gamma 1 \mathrm{y}_{2}=\gamma_{2} \ldots \mathrm{y}_{\mathrm{n}}=\gamma_{\mathrm{n}}\right) \\
& =\prod_{y_{i}=0}\left[1-F\left(X_{i} \beta\right)\right] \prod_{y_{i}=1} F\left(X_{i} \beta\right)
\end{aligned}
$$

It can be written in the concise form as follows:

$$
L=\prod_{y_{1}=0}^{n}\left[F\left(X_{i} \beta\right)\right]^{y_{i}}\left[1-F\left(\mathrm{X}_{i} \beta\right)\right]^{1-y_{i}}
$$

When

$$
F\left(X_{i} \beta\right)=\frac{1}{1+e^{-x_{i} \beta}}
$$

$\mathrm{L}=$ probability that the saving for production possess strength.

On the other hand, the independent variables affecting the strength in the saving for production groups included $\mathrm{X}_{1}$ as age of the groups (years), $X_{2}$ as number of members at the beginning of the groups (persons), $\mathrm{X}_{3}$ as amount of total saving at the beginning (Baht), $\mathrm{X}_{4}$ as amount of collective share value of the groups, $\mathrm{X}_{5}$ as acquisition of the committee, $\mathrm{X}_{6}$ as total number of the group members, $\mathrm{X}_{7}$ as punctual reimbursement of the members with the loan, $\mathrm{X}_{8}$ as rule and regulation 
setting, $\mathrm{X}_{9}$ as operation planning, $\mathrm{X}_{10}$ as members' participation in decision making on operation, $\mathrm{X}_{11}$ as annual ordinary meeting, $\mathrm{X}_{12}$ as member registration, $\mathrm{X}_{13}$ as connection of the group capital with any other groups or organizations, $\mathrm{X}_{14}$ as financial document management of the group, $\mathrm{X}_{15}$ as profit and loss statement preparation, $\mathrm{X}_{16}$ as balance sheet preparation, $X_{17}$ as participation in trainings, seminars, and observation activities related to capital management of the committee in the past year, $\mathrm{X}_{18}$ as exchange of concepts, principles, and operational methods to develop the community between the committee and the external organizations in the past year, $\mathrm{X}_{19}$ as management of welfare thoroughly distributed to the group members, poor households, and the underprivileged, $\mathrm{X}_{20}$ as defining the roles of the committee to strengthen the group, and $\mathrm{X}_{21}$ as appropriate management and thorough distribution of welfare for its member to strengthen the group [19-23].

\section{Discussion}

According to Table 1, the findings shows that Log likelihood function value is -289.9680 , Restricted log likelihood value is -375.045 , Chi- squared value is 134.1541 , McFadden $\mathrm{R}^{2}$ value is 0.1878 , and accuracy value of the model used in the prediction is $79.53 \%$. In addition, there are 10 factors affecting the strength of the saving for production groups in the upper northern areas with the statistical significance at $90 \%, 95 \%$, and $99 \%$ confidence intervals [24-27]. The most influential factor affecting an increase in the strength of the groups is appropriate management and thorough distribution of welfare for the members to strengthen the groups $\left(\mathrm{X}_{21}\right)$ which the possibility of higher strength is $30.43 \%$. The following factor is the total number of the group members $\left(\mathrm{X}_{6}\right)$ that means the possibility of higher strength is $18.20 \%$ when the number of the group members increases. Moreover, it was found that member registration $\left(\mathrm{X}_{12}\right)$, connection of the group capital with other groups or organizations $\left(\mathrm{X}_{13}\right)$ resulted in higher strength at 17.26$15.68 \%$. There are several factors resulting in a decrease of the group's strength at around 5-1\% which include acquisition of the committee $\left(\mathrm{X}_{5}\right)$, rule and regulation setting $\left(\mathrm{X}_{8}\right)$, members' participation in decision making on operation $\left(\mathrm{X}_{10}\right)$, and participation in trainings, seminars, and observation activities related to capital management of the committee in the past year $\left(\mathrm{X}_{17}\right)$.

\section{Management description}

In addition, the in-depth interviews revealed that 352 saving groups (54.15\%) had set the rules and regulation through civil society forum or written record and those conformed to the current situation, 367 (56.46\%) saving groups had created operational plans and followed those plans. Also, 319 saving groups, which was the highest number, had organized annual ordinary meeting and the attendance ratio was higher than $75 \%$.

\begin{tabular}{|c|c|c|c|c|c|c|}
\hline \multirow[t]{2}{*}{ Variable } & \multicolumn{3}{|c|}{ Maximum Likelihood Estimate } & \multicolumn{3}{|c|}{ Marginal Effect } \\
\hline & Coefficient & Standard error & T-stat & Coefficient & Standard error & T-stat \\
\hline Constant & -7.55199 & 1.47399 & $-5.124^{* * *}$ & -1.11727 & 0.19908 & $-5.612^{* * *}$ \\
\hline$x_{1}$ & 0.02643 & 0.01902 & 1.389 & 0.00391 & 0.0028 & 1.393 \\
\hline $\mathrm{X}_{2}$ & 0.00135 & 0.00153 & 0.887 & 0.0002 & 0.00022 & 0.887 \\
\hline$X_{3}$ & 0.00001 & 0.00003 & -0.532 & 0 & 0 & -0.532 \\
\hline$X_{4}$ & 0.00229 & 0.00284 & 0.807 & 0.00033 & 0.00041 & 0.808 \\
\hline$X_{5}$ & -0.11387 & 0.21662 & -0.526 & -0.01696 & 0.03248 & -0.522 \\
\hline$x_{6}$ & 1.10991 & 0.21441 & $5.176^{* * *}$ & 0.182 & 0.03796 & $4.795^{\star * *}$ \\
\hline$x_{7}$ & 0.22356 & 0.4677 & 0.478 & 0.03522 & 0.07822 & 0.45 \\
\hline$x_{8}$ & -0.27745 & 0.2503 & -1.108 & -0.04136 & 0.03753 & -1.102 \\
\hline$X_{9}$ & 0.10186 & 0.24509 & 0.416 & 0.01528 & 0.03727 & 0.41 \\
\hline$x_{10}$ & -0.35303 & 0.24236 & -1.457 & -0.0506 & 0.03347 & -1.512 \\
\hline$x_{11}$ & 0.37778 & 0.23723 & 1.592 & 0.05607 & 0.0353 & 1.588 \\
\hline$x_{12}$ & 2.46219 & 1.12705 & $2.185^{\star}$ & 0.17267 & 0.02781 & $6.209^{* * *}$ \\
\hline$X_{13}$ & 0.93606 & 0.24003 & $3.900^{\star \star \star *}$ & 0.15685 & 0.04403 & $3.562^{\star \star \star}$ \\
\hline$X_{14}$ & 0.512 & 0.27082 & $1.891^{*}$ & 0.07012 & 0.03409 & $2.057^{\star *}$ \\
\hline$X_{15}$ & 0.61464 & 0.34957 & $1.758^{\star}$ & 0.08321 & 0.04294 & $1.938^{*}$ \\
\hline$x_{16}$ & 0.58146 & 0.31429 & $1.850^{*}$ & 0.08205 & 0.04207 & $1.950^{*}$ \\
\hline$x_{17}$ & -0.06227 & 0.45031 & -0.138 & -0.00905 & 0.06433 & -0.141 \\
\hline$X_{18}$ & 0.7852 & 0.4031 & $1.948^{*}$ & 0.01405 & 0.08405 & $1.672^{*}$ \\
\hline$X_{19}$ & 0.69202 & 0.22064 & $3.136^{\star \star \star}$ & 0.10342 & 0.0331 & $3.124^{\star \star \star}$ \\
\hline$X_{20}$ & 1.0117 & 0.67373 & 1.502 & 0.10961 & 0.0501 & $2.188^{* *}$ \\
\hline$x_{21}$ & 1.47769 & 0.51974 & $2.843^{* * *}$ & 0.30428 & 0.12604 & $2.414^{* *}$ \\
\hline
\end{tabular}

\section{Source: Calculation}

Remarks: ** Statistical significance level of 0.01

** Statistical significance level of 0.05

* Statistical significance level of 0.10

Log likelihood function -289.9680

Restricted log likelihood -357.0451

Chi-squared 134.1541

McFadden R2 0.1878

Accuracy prediction $79.53 \%$ 


\section{Problems, Obstacles and Necessity of the Saving for Production Groups}

According to the study results, it was found that the saving for production groups still required the support from the government. The survey found that the most important problem of the groups was little capital for the investment and inadequate circulating funds to fulfill the needs of the members when 607 groups faced the problem most, 443 groups confronted the problem of inability in paying debt on due date, and 410 groups had the problem of delay in remitting money to the saving. Besides, 402 groups faced the problem of data storage and management in the computerized system and 386 groups confronted the problem of inadequate loan for the members' needs [28-30].

Assistance required from the government sectors to promote and aid can be concluded as follows.

(1) The assistance needed from the department of community development - There were 391 groups which were the highest number requiring the promotion and provision of knowledge in saving to the members. Also, there were 251 groups asking for the funds for organizing the activities of the group, 241 groups requiring techniques and instruction in managing the group, 235 groups claiming the understanding of finance and credit, 212 groups requesting the potential development of the committee, and 189 groups expecting the observation activities to exchange and learn among the strong saving groups [31]

(2) The assistance required from the Bank of Thailand - There are 145 groups asking for the accounting system in the saving groups, 143 groups expecting the assistance in budget and circulating funds added into the saving of the members for taking on loan, 136 groups claiming the budget for constructing offices to operate the saving groups, 126 groups asking for the loan with low interest offered to the saving groups, 90 groups expecting year-to-year loan and reimbursement without interest, etc.

(3) The assistance needed from other sectors - There are 274 groups requiring the support of computers to the saving groups, 176 groups asking for budget and circulating funds added into the saving groups, 167 groups claiming the development for strengthening the potential among the members of the saving groups, 161 groups expecting the support in community enterprise finance from the sub-district administrative office, 143 requesting initial concepts, knowledge, and academic matters for the groups and their members, 136 groups requiring occupation development for the members, 134 groups expecting more observation activities and additional budget from the government sectors to manage welfare for the members [32,33].

\section{Recommendations for Policy}

The findings from the study on the factors influencing the strength of the saving for production groups, problems and obstacles in operating the saving groups, and the necessity of the saving groups, can be concluded as recommendations for many sectors regarding policy making which is related to the saving for production groups as follows.

\section{1) The Office of Community Development should}

a. Encourage the committee of each saving group to exchange the concepts, principles, and operation methods to develop the community with the external organizations

b. Follow and inspect the registration to keep it accurate and up-to-date c. Follow and promote the saving groups to define the roles and responsibilities of the committee and to closely evaluate the group's operation

d. Provide knowledge regarding the objectives of establishing the saving groups from the beginning, the management especially in finance, and being an escort the groups till the groups can manage all by themselves

e. Increase the income of the saving groups by promoting the members to have part-time self-employment and find the chances or markets to sell those products or commodities

f. Follow the operation of the saving groups closely at the initial stage of establishment

g. Prepare the stage for the saving groups with success in operation to share knowledge, management methods with other group members to apply in their groups

h. Organize the meeting/training for the group members or organize the training for specific positions such as committee members, treasurers, accountants, etc in order to spread the news, information, and knowledge to the members to apply in their groups

i. Cooperate with other sectors such as commercial banks, to provide knowledge about investment in order to increase their income as well as to provide knowledge about financial management in deposit and loan of the group

2) The Bank of Thailand should take actions and operate through the commercial banks in the following ways

a. The commercial banks should be the advisors for the saving groups including the deposit management, loan approval consideration for the members as well as suggesting types of financial investment to the groups.

b. The commercial banks should fix the lower interest rate for the credit of loan than other types of loan services in order to allow the groups to construct the offices of the groups, to promote jobs, or they should indicate the due date of reimbursement without interest, or longer loan period with lower interest rate.

3) Other sectors such as local administrative organizations, schools, colleges, or universities through

a. The local administrative organizations, by emphasizing the importance of establishing and operating the saving groups by adding the activities of the groups into the annual operation plans, organizing the training to provide knowledge to the members, encouraging the members to earn income from part-time self-employment, or creating observation activities to visit the operation of the successful saving groups.

b. Obtain the ability of accounting, there should have the students from the vocational colleges or university ones provide knowledge in accounting. Not only the students are able to apply their knowledge, but the members of the groups also obtain knowledge regarding correct accounting.

c. Promote the occupation and to find the channels to distribute the products, the groups may need to request for the cooperation from university to conduct research or to develop and design the products to meet the customers' needs and to increase the income of the groups. 
Citation: Sriwichailamphan T, Sucharidtham T (2016) Factors Affecting the Strength of Production - Oriented Savings Groups in the Upper North Thailand. Int J Econ Manag Sci 5: 313. doi:10.4172/2162-6359.1000313

Page 5 of 5

\section{References}

1. Community Development Department (2000) Handbook of Production-oriented Savings Groups Promotion and Network Activities, Bangkok.

2. Community Development Department (2003) Community Enterprise Operation Process of Enterprises Promotion Office.

3. Community Organizations Development Institute, Ministry of Social Development and Human Security (2003) 10th Year Heartfelt Center Village Bank, Commitment, Problem Solving, and Local Community Development, Dok Kham Tai District.

4. Local Community Rehabilitation: Alternatives and Opportunities of Community Development in Globalization (2012).

5. Kingkaew I (1989) The Operation of Production-oriented Savings Groups and Rural development. Bangkok.

6. Tawinwadee B (2005) Complete Research Report of Traffic Accident Prevention Policy Evaluation. Nontaburi: King Prajadhipok's Institute.

7. Thanes S (1999) Denying Production-oriented Savings Groups of People in the Operation Area of Chiang Mai Province, Chiang Mai: Faculty of Economics, Chiang Mai University.

8. Songsak S (2003) Econometrics. Chiang Mai: Faculty of Economics, Chiang Mai University.

9. Paiboon W, Panthip P (2001) Financial System for the Low Income (Micro Banking), Bangkok: Community Organizations Development Institute.

10. Peem P (2003) Ways and Power of Community Financial Organization Case Study of Community Financial Organization 7 in Nakhon Si Thammarat.

11. Montri P (1999) Self-reliance Community Economy of Production-oriented Savings Groups in Lampang Province. Independent Study in Economics, Chiang Mai University.

12. Mukda I (2012) Heartfelt Center Village Bank, Dok Kham Tai, Payao Province.

13. Thailand Development Research Institute Foundation (2004) Complete Study Report of Research Project for Micro-finance System Development.

14. Rangsan P (2002) Community and Network Financial Organization Development. Bangkok: Faculty of Economics. Kasetsart University

15. Ratanapun S (2003) Factors Strengthening the Community: A Case Study of Tambon Klong Pia Savings Group, Chana District, Songkhla Province. Chiang Mai: Faculty of Economics, Chiang Mai University.

16. Wanna Y (2004) The Operation of Production-oriented Savings Group of Ban Mae Sai Moo 2, Tambon Wiang, Muang, Phayao Province. Chiang Mai: Faculty of Economics, Chiang Mai University.
17. Saisunee K (2004) The Operation of Production-oriented Savings Group of Ban Nong Phra, Moo 3, Tambon Nong Phra, Wang Thong District, Phitsanulok Province. Chiang Mai: Faculty of Economics, Chiang Mai University.

18. Social Fund Office (2001) Community and Network Organization Development Community Lesson No. 8.

19. Social Fund Office (2002) Sajja Savings Group of Chanthaburi Province. Socia Management Unit No. 5

20. Social Fund Office (2002) Sajja Daily Savings Group. Community Knowledge Unit No 5 .

21. Annual Report between 2003-2004: Integration and Rehabilitation toward Stable Locality.

22. Sayomporn L, 30th Year Production-oriented Savings Group: Moral Power Leads Every Community to Solve Problems of Poverty. Bangkok: Community Development Department, Ministry of Interior.

23. Aree C, Thanet S (2001) The Development of Capital Accumulating Group for Community Economic Development in the Northern Area. Chiang Mai: Faculty of Economics, Chiang Mai University.

24. Andrew T (1987) Production, Power and Participation in Rural Thailand: Experiences of Poor Farmer Groups. Geneva.

25. Berndt E, Hall B, Hall R, Hausman J (1974) Estimation and Inference in Nonlinear Structural Models. Ann Econ and Social Measurement 3: 653-665.

26. Greene W (1997) Econometric Analysis ( $5^{\text {th }}$ edn.), Prentice Hall, New Jersey, USA.

27. Gujarati DN (1995) Basic Econometrics (3rd edn.), McGraw-Hill, New York USA.

28. Hanushek EA, Jackson JE (1979) Statistical Methods for Social Scientists Academic Press, New York USA.

29. Johnston J, Dinardo J (1997) Econometric Methods (4th edn.), McGraw-Hill, New York, USA

30. Maddala G (1983) Limited Dependent and Qualitative Variables in Econometrics, Cambridge University Press, New York, USA.

31. Pindyck RS, Rubinfeld DL (1998) Econometric Models and Economic Forecasts ( $4^{\text {th }}$ edn.), McGraw-Hill, New York, USA

32. Suthasupa P (1982) Territory and Rural Development in Thailand. Singapore: Regional Institute of Higher Education, Republic of Singapore.

33. Yaron J (1992) Successful Rural Finance Institutions. Finance and Development pp: $32-35$. 